\title{
On WebQuest-based Metacognitive Speaking Strategy Instruction
}

\author{
Juan Li \\ Ordnance Engineering College, Shijiazhuang, China \\ Email: 1225lijuan@163.com \\ Ying Yue \\ Ordnance Engineering College, Shijiazhuang, China \\ Mifen Yang \\ Ordnance Engineering College, Shijiazhuang, China
}

\begin{abstract}
Under the guidance of WebQuest theory and O'Malley and Chamot's five-step mode strategy learning theory, This paper has designed a WebQuest-based metacognitive strategy learning activity and made it into practice on a college junior class, not only the necessity of strategy training in oral English instruction is highlighted in the study, but also study results show that the designed program has enhanced learners' ability to plan, adjust, and evaluate in oral English learning.
\end{abstract}

Index Terms-WebQuest, metacognitive strategy, oral English instruction

\section{INTRODUCTION}

\section{A. WebQuest}

WebQuest is an instructional procedure or learning plan which is developed by Professor Borne Dodge and Professor Tom March in the year of 1995. According to the complexity of tasks, WebQuest plan can be as short as one course or as long as one week even one month. Learners need to actively participate in certain given activities so as to complete the given tasks through analysis of abundant resources. Generally speaking, a complete WebQuest course is made up of four parts:

In the introduction part, the background information of the learning task is presented and certain learning circumstances are established to inspire learners' interest and to encourage learners to make efforts to solve learning problems.

In the task part, specific task will be described in detail, and learners are asked to hand in a piece of elaborate work which is in the form of a whole document such as a PPT, a Webpage, a report or a paper and so on.

In the resources part (the process part), This part is mainly a material center; some information can be offered in advance as the anchor point for students to search for other information.

In the evaluation part, a certain set of criterions to identify whether the learning achievement are satisfying or not.

\section{B. Metacogniitve Strategies in Oral English (OE)}

Researchers seem to commonly agree that metacognition refers to a persons' cognition about cognition, and during the past few years, researches showed that metacognition plays an important role in language acquisition especially in writing. Studies indicated that metacognition can be taught to learners and metacognitive strategies can be trained, still many experimental studies at home and abroad having shown that metacognitive strategy plays a potential role in promoting oral English. Given the length of this article, those studies and researches will not be detailed illustrated, but the following is an experimental study which will too, re-affirm the idea above. Doutless, while using a language, speakers need to distinguish meaningful information from meaningless information; they also need to recognize their own roles according to the context, whereas these skills are what metacognitive strategies can help with. Therefore, metacognitive speaking strategy instruction is necessary.

\section{Extracurricular Learning}

Since we pay attention to extracurricular English learning in this study, the concept of learner autonomy cannot be overlooked. The term learner autonomy was first put forward by Holec in the 1970s. Holec's definition of learner autonomy was: the ability to take charge of one's own learning and to take charge of one's own learning is to have, to hold, the responsibility for the decisions concerning all aspects of this learning. Ever since the birth of learner autonomy, it has become a hot topic for foreign language educators both at home and abroad. In the recent years, Holec's definition of Learner autonomy has been misunderstood as being no more than self-instruction by many teachers and researchers. Until now, the meaning of this term remains uncertain because different definitions are established by researchers from 
different perspectives.

In recent years, educationists have made great efforts in helping learners study English in out-class environment, and extracurricular activities have been so popularly used since English learning has been hot in China. Newspapers, internet and some other kinds of mediums are all taken advantage of to implement extracurricular learning; meanwhile, with the development of new technology, various materials including audio, video tape and other digital materials online have appeared. The appearance of various digital materials proves that the learning of English enjoys a more particular advantage in the Web-based learning environment compared with the learning of other knowledge; to optimize the effectiveness of language teaching, teachers should and must best explore the potential of extracurricular learning space.

\section{RESEARCH DESIGN}

The current study is aimed at designing a WebQuest-based Training (WQT) program and applying it to an experimental study. The following two questions need to be answered:

Firstly, whether Integrating WebQuest construction into metacognitive strategy training steps is feasible or not?

Secondly, whether the WQT program could enhance learners' ability to plan, adjust, and evaluate their oral English or improve their speaking performance.

The subjects of the experiment were 60 college junior students chosen from a millitary college. The subjects took part in the regular OE course (five-week optional course). They met twice a week, every time in 100-minute classes, instructed by the same teacher, and followed the same syllabus. In light of WebQuest-based instruction, the subjects were divided into six groups on the basis of voluntary, they are required to collaborate after class in order to construct a complete set of WebQuest regarding the three different metacognitive strategies(self-planning, self-monitoring and self-evaluation). Our instructions for WebQuest construction focus on the following four aspects:

Firstly, in the introduction part, after each group has chosen one metacogntive strategy as their common topic. Teachers tells the learners that the aim of this part is to present background information of the learning task, and then certain learning circumstances can be established to inspire the other learners' interest and to encourage them to make efforts to solve relevant learning problems.

Secondly, in the task part, the requirements are: specific task should be described in detail by each group according to their chosen topic, and a piece of elaborate work which is in the form of a whole document such as a PPT, a report or a paper and so on should be specifically requested. The most important thing is that those works should be authentic, feasible and attractive to students.

Thirdly, the resources part is mainly finished by the teachers, but learners are authorized to renew or complement it with their own materials.

Lastly, in the conclusion part, and designers are required to set up certain set of criteria to identify whether the learning achievement are satisfying or not , the criteria should be clear and easy to understand by learners. Each group should present their WebQuest so as to be shared by other groups.

Totally, There are four weeks to do the instruction (as required, the foreign teacher will give lectures for one week, thus the three metacognitive strategies are distributed in three weeks respectively and the last week was for teacher to make evaluation), Two parallel components were consisted of in the procedure of data collection: quantitative and qualitative parts. In the quantitative part, all sixty students were asked to answer two questionnaires regarding their speaking preferences and views on oral English instruction. The former questionnaire before the learning program was to explore the level of students' metacognitive awareness, and students' expectations for oral language teaching were also identified. The latter questionnaire was conducted after the program; the purpose was to see whether any changes in students' metacognitive awareness have occurred and whether this kind of program is acceptable to students. All questions were designed with a 5-point scale, from strongly agree to strongly disagree.

In the qualitative part, six of the subjects were chosen to accept interviews respectively before and after the WQT program. Interviews before the learning were to supplement with some information about students' difficulties in oral English and their current knowledge about metacognitive strategy. Both of the quantitative and qualitative data were equally important since they answered the same set of questions from different perspectives.

\section{Results ANALYsis}

\section{A. Attitudes toward English Oral English and Oral English Instruction}

As the table below has shown: most of the students have realized the importance of oral English in their English study, and they indeed have made many efforts to improve oral English performance, but few of them consider that their current oral English achievement is as satisfying as what they expect (Means=3.25). Therefore, students hold great expectation for improving their oral English performance with the help of teachers. 
TABLE 3.1

INFORMATION OF WEBQUEST ACTIVITY

\begin{tabular}{l|l|l}
\hline \multirow{2}{*}{ Item } & Experimental group \\
\cline { 2 - 3 } & Means & St.d \\
\hline I think oral English plays an important role in English study. & $\mathbf{1 . 3 0}$ & $\mathbf{0 . 4 4}$ \\
\hline I make great efforts to practice oral English. & $\mathbf{1 . 2 9}$ & $\mathbf{0 . 6 8}$ \\
\hline I am satisfied with my oral English. & $\mathbf{3 . 2 5}$ & $\mathbf{0 . 5 5}$ \\
\hline I know how to learn oral English well & $\mathbf{3 . 6 1}$ & $\mathbf{0 . 8 1}$ \\
\hline I am satisfied with the current teaching method in oral English class & $\mathbf{2 . 3 1}$ & $\mathbf{0 . 6 4}$ \\
\hline $\begin{array}{l}\text { I hope the teachers could offer more help and guidance for me to practice } \\
\text { oral English after class. }\end{array}$ & $\mathbf{1 . 7 7}$ & $\mathbf{0 . 4 3}$ \\
\hline
\end{tabular}

\section{B. Attitudes toward WebQuest-based Learning}

As for the popularity and effectiveness of WebQuest-based learning mode, there are six questions concerned. See table 3.2:

Forty-four students out of sixty consider that WebQuest is beneficial to their studies (Item 3). But less than half of the subjects are fully engaged in the learning mode (Item 2), in order to identify the reasons, the experimenter has designed specific interviews with some subjects. It is said that students feel a little at loss at first sight of WebQuest because they have never studied in this way, some reported that they were very suspicious of the effect at first but days later they gradually got enough confidence in themselves because they thought it was funny to do some work like this and they can enjoy their working hours very much. In the end of the learning program, six complete WebQuests are handed in and four of them are done eligibly, they mainly contain the six parts: introduction, task, process, resources, evaluation and conclusion.

TABLE 3.2

INFORMATION OF WEBQUEST ACTIVITY

\begin{tabular}{|c|c|c|c|c|c|c|}
\hline \multirow{2}{*}{ Item } & \multicolumn{5}{|c|}{ Number of students for each Choice } & \multirow{2}{*}{ Mean Score } \\
\hline & 1 & 2 & 3 & 4 & 5 & \\
\hline $\mathbf{1}$ & 32 & 22 & 1 & 1 & & 1.61 \\
\hline 2 & 24 & 26 & 4 & 5 & 1 & 1.90 \\
\hline 3 & 44 & 15 & $\mathbf{1}$ & & & 1.32 \\
\hline 4 & 30 & 18 & 11 & 1 & & 1.77 \\
\hline 5 & 56 & 2 & 2 & & & 1.16 \\
\hline 6 & 28 & 22 & 10 & & & 1.70 \\
\hline
\end{tabular}

\section{Changes of Learners' Metacognitive Awareness}

The mean and standard deviation reflect subjects' awareness and employment of metacognitve strategy. The higher the mean is, the less the subjects are likely to comprehend metacogntive strategy; the higher the standard deviation is, the more different the subjects are in realizing and choosing MS. Since subjects rated their statement on a 5-point scale, the higher the score, the less confirmative answer was made by the students; otherwise it was more agreed by the students.

TABLE 3.3

\begin{tabular}{|c|c|c|c|c|}
\hline \multirow{3}{*}{ Item } & \multicolumn{4}{|c|}{ Exp-group } \\
\hline & \multicolumn{2}{|c|}{ Be-WQ } & \multicolumn{2}{|c|}{ Af-WQ } \\
\hline & means & Sd & means & Sd \\
\hline 1 & 1.26 & 0.56 & 1.02 & 0.44 \\
\hline 2 & 2.33 & 0.79 & 1.05 & 0.29 \\
\hline 3 & 3.49 & 0.76 & 1.26 & 0.54 \\
\hline 4 & 2.89 & 0.52 & 1.47 & 0.56 \\
\hline 5 & 2.77 & 0.45 & 1.14 & 0.58 \\
\hline 6 & 1.36 & 0.71 & 1.07 & 0.55 \\
\hline
\end{tabular}

\section{Effect of WebQuest on Oral English Instruction}

Scores of the following items in table 2.4 has decreased most which indicates that after the WebQuest-based learning of metacognitive strategies, students' metacognitive awareness has improved and they are more willing to conduct self-evaluation and self- planning compared with self-monitoring. The awareness of self-monitoring has also improved, though not as high as that of self-evaluation and self-planning. 
TABLE 3.4

IMPROVEMENTS IN METACOGNITIVE STRATEGY USE

\begin{tabular}{l|l}
\hline I can tell exactly whether I have finished a good or bad oral English task & 1.26 vs. 1.02 \\
\hline I know what my shortcomings and strong points are in oral English. & 1.78 vs. 1.45 \\
\hline I can use strategies to help me speak English better. & 2.21 vs. 1.17 \\
\hline I make plans for achieving oral English goals. & 2.33 vs. 1.05 \\
\hline I always check whether I have carried out the oral English plans well. & 2.77 vs.1.14 \\
\hline
\end{tabular}

\section{FINDINGS AND RECOMMENDATIONS}

Although there are some limitations regarding this study. First, the focus on the non-English majors limits generalization to learners in other regions. Second, the current research held a high demand for teachers who should have a knowledge system about WebQuest and constructivist theory, since it is difficult to find another teacher that is qualified for the work, only the experimenter herself as an instructor has taken part in the experiment. The main findings of this study are given below:

Firstly, the necessity of improving oral English instruction is highlighted. Compared with other students in universities, military college students are a special group of English learners in China: firstly, students in MC spend less time studying English because of other tough work and responsibilities; secondly, after graduation more practical ability are required for MC students. In consideration of the above factors, practical and effective ways should be found to better MC students' oral English instruction.

Secondly, WebQuest is a very good way to realize students' extracurricular learning under teachers' guidance. WebQuest has a great significance in assisting college students in autonomous learning, cooperative study and creative ability.

Thirdly, students had a favorable perception of the WebQuest-based learning. The WQL (WebQuest-based Learning) mode does facilitate instruction. As a learning outcome of the experiment, students improved their knowledge of metacognitive strategies, strengthened their metacognitive awareness. The experiment has also indicated that the metacognition-centered learning based on WebQuest was effective in promoting speakers' proficiency.

In all, Metacognitive strategies could be well mastered through self-construction of WebQuest. By developing students' capacity for becoming autonomous learners, metacognitive awareness in oral English learning has been strengthened.

Still some recommendations:

1. Students in Millitary College hold high expectations for improving their oral English, since class time is limited for students to study oral English, it is necessary and feasible for teachers to take advantage of extracurricular time to optimize oral English instruction.

2. Metacognitive awareness is a significant factor that affects learners' performance, both teachers and researchers should pay special attention to learners' metacognitive awareness training.

3. Teachers should, on one hand, take full advantage of extracurricular activities to encourage and guide students to use metacognitive strategies in English learning; on the other hand, tools like emails, OICQ, WebQuest, Weblogs or any other techniques to learn metacognitive strategies, activities such as group work, reviewing and discussion are suggested.

All in all, with the development of information age in which more and more teachers and students can easily get access to internet, the application of WebQuest in students-centered learning should and will display its great potentials in many ways, oral English instruction based on WebQuest in China leaves much room for teachers to take practice.

\section{REFERENCES}

[1] Abbey, B. (2003). Instructional and Cognitive Impacts of Web-Based Education. Beijing: China Light Industry Press.

[2] Bernie, D. Some Thoughts about WebQuests. Http:// b.sdsu.edu/courses/edtec596/about_webquests.html. (accessed 2/4/2008).

[3] Christine, C. M. (1997). Chinese ESL Students' Learning Strategies: A Look at Frequency, Proficiency, and Gender. Journal of Applied Linguistics, 2 (1), 39-53.

[4] Cohen, A. D. (2000). Strategies in Learning and Using a Second Language. Beijing: Foreign Language Teaching and Research Press.

[5] Cuban, (1996). Computers in the Classroom: Revolutions that Fizzled, New York: Washington Post, $34-57$.

[6] Liu, Runqing \& Dai, Manchun. (2003). Study on Foreign Language Teaching and Learning Reform in China, Beijing: Foreign Language Teaching and Research Press.

[7] O'Malley, J.M. \& A.U. Chamot. (1990). Learning Strategies in Second Language Acquisition, Cambridge: Cambridge University Press.

[8] Zoltan, (2003). Questionnaires in Second Language Research: Construction, Administration, and Processing. Mahwah, N.J: Lawrence Erlbaum Associates. 
Juan Li was born in Handan, China in 1982. She received his M.A degree in literature from Hunan University, China in 2008.

She is currently an instructor in the Department of Foreign Languages, Ordnance Engineering College, Shijiazhuang, China. Her research interests include language instruction and language testing.

Ying Yue was born in China in 1956. She graduated from Luo Yang Foreign Lauguage University, China.

She is currently an associate professor in the Department of Foreign Languages, Ordnance Engineering College, Shijiazhuang, China. Her research interests include language instruction and language testing.

Mifen Yang was born in Shijiazhuang, China in 1982. She received his M.A degree in literature from Hebei University, China in 2009.

She is currently an instructor in the Department of Foreign Languages, Ordnance Engineering College, Shijiazhuang, China. Her research interests are translation and language instruction. 